\title{
CONDUTA BÁSICA DE ENFERMAGEM NA DOENÇA MENINGOCóCICA
}

\section{Yoriko Kamiyama*}

KAMIYAMA, Y. Conduta básica de enfermagem na doença meningocócica. Rev. Esc. Enf. USP, São Paulo, 15(2):161-171, 1981.

Descrição dos principais problemas de pacientes portadores da doença meningocócica $e$ da conduta básica de enfermagem no seu controle.

\section{I - INTRODUÇÃO}

A doença meningocócica, causada pela Neisseria meningitidis, vem constituindo motivo de grande preocupação entre nós, pela gravidade com que se manifesta e pelas profundas repercussóes sociais que causa a sua natureza contagiosa.

A percepção da sociedade em relação a doenças contagiosas é, de modo geral, altamente negativa. Os próprios doentes internados em Unidades de Isolamento interpretam esse tipo de doença como "uma das piores doenças" ou "doença que todos temem" 8 .

Dessa forma, além do trauma físico provocado pela patologia, o indivíduo que adquire tal tipo de doença experimenta sérios problemas de ordem psico-social tais como: insegurança, sentimento de rejeição, desconforto relacionado ao isolamento, preocupações em relação à contagiosidade da doença e outros.

$\mathrm{O}$ receio do contágio atinge também a família e, de modo mais amplo, a comunidade, sobretudo quando se trata de enfermidade que possa incidir sob forma epidêmica, como no caso da doença meningocócica.

Essa doença infecciosa aguda, caracterizada por hipertermia, cefaléia intensa, vômitos em jato, sinais de meningismo, por vezes acompanhada de exantema petequial, sufusões hemorrágicas, delírio e choque, vem preocupando a população brasileira principalmente em São Paulo, em virtude dos surtos epidêmicos ocorridos no periodo de 1971 a 1977.

A literatura especializada ${ }^{2,3,9,10}$ identifica-a da seguinte forma: doença cosmopolita; incide praticamente no mundo todo, em caráter endêmico com surtos epidêmicos esporádicos; ocorre tanto em regióes quentes quanto em frias, sendo mais comum em zonas de clima temperado.

Em relação à distribuição sazonal, observa-se ligeira elevação na incidência durante a primavera e o inverno.

Normalmente, o coeficiente de morbidade é de 2 a 4 por 100.000 habitantes, indice esse que se eleva a 30 ou mais em épocas de epidemia.

\footnotetext{
* Professor Livre-Docente da disciplina Enfermagem em Doenças Transmissíveis da EEUSP.
} 
A fonte de infecção é o homem e a transmissão dá-se pelo contágio direto inter-humano.

Embora a susceptibilidade ao microrganismo seja geral, a maioria dos indivíduos convive, em equilíbrio, com o germe, no seu eco-sistema, sem se tornar doente.

Existem alguns fatores predisponentes que favorecem a instalação da doença tais como: baixa idade, desnutrição, doenças de base, promiscuidade, excessivo desgate físico e outros ${ }^{1,2,9,10}$.

0 germe atinge o susceptível pelas vias aéreas superiores, localizando-se em seguida na orofaringe, de onde, por contiguidade, pela via hemática ou ainda acompanhando as bainhas dos nervos cranianos, alcança as meninges, produzindo sua inflamação. Pode também permanecer na circulação provocando a meningococcemia.

O quadro clínico é muito variável, porém as formas mais comuns são as de meningite e meningococcemia, geralmente graves.

\section{II - O PACIENTE DE DOENÇA MENINGOCóCICA E SEUS PROBLEMAS}

Muitos são os problemas enfrentados pelo paciente acometido pela doença meningocócica.

Além das lesões patológicas, do desconforto e insegurança inerentes à própria doença, o doente experimenta sérias preocupaçóes relacionadas à natureza transmissível da afecção, tais como: medo do aparecimento de novos casos na família, sentimento de vergonha por ter adquirido esse tipo de afecção, sensação de ser indesejável aos outros, desconforto e estresses gerados pelo tratamento agressivo e pelo ambiente traumatizante que é o isolamento.

Analisadas à luz das necessidades básicas humanas, que são parâmetros para identificação dos problemas do paciente, as alterações mais significativas em pacientes de doença meningocócica são detectadas em relação às seguintes necessidades: integridade física e cutâneo-mucosa; regulação imunitária, térmica, neurológica, vascular; eliminação; motilidade e mecânica corporal; percepção visual, auditiva e dolorosa; ambiente; terapêutica; segurança; autonomia; informação; consideração e necessidade social.

Os problemas encontrados com maior frequiência são a seguir descritos.

Sinais e sintomas da doença

Em geral, 2 a 10 dias após a agressão pelo germe, começam a se evidenciar os primeiros sintomas: faringite, rinite, febre e mal estar geral. Em seguida, instala-se o quadro de meningite ou de meningococcemia.

$\mathrm{Na}$ meningite distinguem-se três síndromes principais: $10^{\circ}$ - infecciosa (mal estar geral, febre, calafrios, toxemia e prostração); $2 .^{\circ}$ radicular (rigidez de nuca, sinais de Brudzinski, Koernig e Lasègue positivos e posição de opistótomo) e $3 .^{\circ}$ - hipertensão endocraniana (cefaléia intensa, fotofobia, vômitos em jato, edema papilar e parestesias). 
Podem também surgir sinais e sintomas de encefalite tais como: convulsões, paralisia, tremores, hipoacusia, ptose palpebral, nistagmo, etc. 1,2,3,5,9,10,11.

Segundo a literatura ${ }^{3}$ a meningite meningocócica representa $40,4 \%$ das meningites purulentas.

A meningococcemia caracteriza-se por início repentino, hipertermia, mialgia, prostração, mal estar geral, exantema petequial e sufusões hemorrágicas. Nas formas fulminantes, freqüentemente sobrevém a morte ${ }^{10}$.

\section{Presença de elementos contaminantes}

Nas primeiras 24 horas do tratamento antibiótico, o doente oferece risco de transmissão do agente etiológico pelo contágio direto, mediante secreções da orofaringe, das lesões cutâneas e pelo sangue.

Receio da própria doeņ̧a e preocupações com a sua evolução

O receio da doença, do prognóstico, da possibilidade de instalação de complicações e seqüelas sempre está presente.

Tal receio origina-se à suspeita da doença e agrava-se quando é feita a diagnose. Esta é feita pelo exame clínico consolidado pelo exame laboratorial do líquido céfalo-raquidiano constando de: bacterioscopia, cultura e estudo quimiocitológico.

Hemocultura, pesquisa de anticorpos, exame do material das lesões cutâneas e de secreções de orofaringe são feitos segundo a fase da doença, condições clínicas do paciente e recursos disponiveis ${ }^{10}$.

Na meningite meningocócica, o líquido céfalo-raquidiano apresenta-se geralmente purulento, com grande número de células e de neutrófilos.

A taxa de cloretos e de glicose está diminuída e a quantidade de células aumentada.

Em geral, a doença meningocócica é interpretada pela população como doença de extrema gravidade e que deixa seqüelas irreversíveis. Freqüentemente são encontrados pacientes que, embora apresentando boa evolução, expressam grande dúvida quanto à sua recuperação, bem como receio de se tornar inválidos.

Realmente, trata-se de doença geralmente grave. Porisso, confirmado o diagnóstico ou mesmo em cas de suspeita, imediatamente deve ser iniciado o tratamento.

São utilizadas as medidas gerais de sustentação e de levantamento do estado geral, e, como tratamento específico, é administrada Penicilina (Penicilina cristalina ou Ampicilina) por via endovenosa. Os glicocorticosteróides são usados para reduzir o edema cerebral e em casos de choque ${ }^{1,2,3,10}$.

Outros medicamentos sintomáticos são utilizados tais como: anti-eméticos, anti-térmicos, anticonvulsivantes, anticoagulantes, etc., segundo a necessidade do paciente ${ }^{1,2,3,9}$. 
0 tratamento precocemente instituido e corretamente conduzido é fundamental para o êxito na recuperação do paciente. $O$ índice de letalidade, em 1973, segundo dados do Hospital Emílio Ribas citado por BASTOS ${ }^{2}$, foi de $3,4 \%$ em relação a todos os óbitos por essa doença e de $3,5 \%$, se descontadas as mortes ocorridas nas primeiras 24 horas de internação.

As principais complicações e seqüelas que muito preocupam os doentes, familiares e equipe de saúde são: miocardite, choque toxêmico, conjuntivite, panoftalmia, uveite, coleçōes subdurais, hidrocefalia, cegueira, surdez, distúrbios do comportamento, artrites supurativas, necroses, gangrena de extremidades, etc ${ }^{1,2,3,10}$.

\section{Desconforto provocado pelo isolamento}

A unidade de isolamento é considerada altamente estressante em virtude da restrição da liberdade, do espaço e do contato interpessoal. Freqüientemente os pacientes queixam-se de que o isolamento é "semelhante à prisão", ambiente que gera "angústia", "desespero" e "nervosismo".

Ainda, a experiência de trabalho junto a pacientes contagiosos, mostra que tanto estes quanto seus familiares tendem a associar o isolamento com maior gravidade do caso.

As técnicas de isolamento adotadas pela equipe assistencial são também fatores que aumentam o desconforto e estresse dos internados ${ }^{7,8}$.

Preocupação, receio e desconforto relativos à natureza contagiosa da doença.

A possibilidade de aparecimento de novos casos na família é uma das maiores preocupações expressas não só pelos pacientes mas também pela família. Ambos, de modo geral, quase nada conhecem sobre a doença e mostram-se altamente motivados em obter informações corretas e seguras sobre o mal, principalmente no tocante ao prognóstico, mecanismo de transmissão e medida de profilaxia.

Muitos pacientes referem ter-se ressentido a rejeição de que foram alvo, quando da elucidação do diagnóstico e mormente após a internação ${ }^{4,8}$.

$O$ sentimento de ser indesejável para os outros, de revolta e de vergonha por ter adquirido uma afeç̧ão de caráter contagioso é referido por numerosos doentes.

Por outro lado, companheiros de trabalho do paciente, seus chefes e até mesmo familiares, em alguns casos, têm demonstrado atitudes de afastamento e rejeição, fatos ocorridos com relativa freqüência durante a epidemia de 1971 a 1977.

Não são raros os que se preocupam com a possivel recusa do retorno ao emprego ou da reintegração nos grupos sociais de origem, após a alta.

\section{Insegurança}

A situação de crise, inerente à hospitalização, é mais intensa quando se trata de doença grave e que constitui alvo de estigma social. A imposição de dependên- 
cia e a perda de autonomia, a incerteza do sucesso do tratamento a percepção de ameaça à vida, e a perspectiva de internação prolongada são fortes componentes que aumentam a insegurança do individuo.

Estresse provocado pelo tratamento agressivo.

A punção lombar necessária para o diagnóstico e controle da evolução, a administração freqüente e prolongada de medicamentos por via intravenosa, a aplicação de medidas rígidas de contenção física para evitar quedas do leito, os cuidados de terapia intensiva, por vezes necessários são motivos de forte estresse para o paciente.

Pela natureza dos problemas e das necessidades afetadas, nota-se que, mesmo sendo a doença meningocócica geralmente grave, a assistência de enfermagem recai prioritariamente na área expressiva e não na instrumental.

\section{III - CONDUTA BÁSICA DE ENFERMAGEM}

É axioma básico da assistência de enfermagem a pacientes hospitalizados, independentemente da patologia de que são portadores, a compreensão do ser humano como um todo bio-psico-social que apresenta as necessidades básicas afetadas por aquela situação - estar doente e hospitalizado.

A conduta de enfermagem deve ser dirigida para atender globalmente o indivíduo, orientada pelos problemas de enfermagem que são os sinais e sintomas indicativos da alteração das necessidades básicas provocadas pela doença.

Como as necessidades básicas são interrelacionadas, o desequilíbrio de uma necessidade afeta as demais, em maior ou menor grau, tanto no nivel fisiológico como no psico-social ${ }^{6}$. Ainda, a natureza essencialmente social do ser humano reclama o atendimento dos problemas relativos à familia e a outros grupos sociais.

O êxito da assistência de enfermagem repousa na correta identificação dos problemas do paciente, no planejamento e na implantação de ações para o seu atendimento.

Ações de enfermagem no atendimento ao paciente com doença meningogócica

1 - Isolamento

- Instalação e manutenção do "isolamento respiratório", com utilização de quarto individual ou privativo para esse tipo de doença, durante as primeiras 24 horas do tratamento antibiótico. Em casos de meningococcemia, o isolamento deverá ser "total".

- Identificação do isolamento por meio de cartão específico colocado na porta do quarto. Esse cartão deve conter o tipo de isolamento, os procedimentos e técnicas específicas e orientação para os visitantes procurarem a enfermeira antes de entrar no quarto. Devem constar do verso 
do cartão as doenças ou as condições que requerem o referido tipo de isolamento.

- Suspensão do isolamento após 24 horas de tratamento antibiótico.

- Provimento de todo material necessário, privativo para o paciente e para os cuidados com o ambiente da unidade.

- Orientação da equipe de enfermagem sobre esse tipo de isolamento.

2 - Assistência na admissão do paciente.

- Admissão direta no quarto.

- Rápida verificação das condições do paciente e atendimento aos problemas prioritários.

- Se o estado do paciente permitir: Diminuição da insegurança do recém admitido, por meio de atenção psicológica e de orientação precisa sobre sua situação, o ambiente de isolamento, o mecanismo de transmissão, a equipe por ele responsável, regulamento do hospital, etc.

3 - Administração de medicamentos.

- Restrição do paciente, se necessário.

- Rápida introdução do medicamento específico e manutenção correta da administração do esquema de tratamento.

- Manutenção da veia com soro glicosado a $5 \%$.

- Observação das reações ao medicamento.

- Adequação da administração dos medicamentos "se necessário", às condições do paciente e rotinas do hospital.

4 - Cuidados com o ambiente e material.

- Preparo e manutenção de ambiente calmo, limpo e arejado.

- Limpeza concorrente diária.

- Limpeza terminal na alta abrangendo, além da desinfecção química, a exposição aos raios ultra-violetas durante 2 horas.

- Esterilização, no término de cada plantão, dos panos de chão utilizados na limpeza da unidade.

- Utilização da técnica de manejo de material contaminado para a manipulação de todo material contaminado, roupas, louça e lixo.

5 - Alimentação e hidratação.

- Ajuda adequada às necessidades de alimentação do paciente.

— Observação da aceitação. 
- Tratamento das lesões da boca antes das refeições (limpeza com água bicarbonatada a $2 \%$ ou $3 \%$ e aplicação de xilocaina, 10 a 15 minutos antes das refeições).

- Introdução de sonda nasogástrica na iminência do estado de coma.

- Cuidados normais com a alimentação por sonda nasogástrica e retirada da mesma o mais cedo possivel.

6 - Sono, repouso e movimentação.

— Manutenção da posição antálgica adotada pelo paciente.

- Proteção contra quedas do leito.

- Estímulo à movimentação e deambulação precoce.

- Mudança de decúbito segundo as necessidades do paciente.

7 - Higiene corporal.

- Banho com água morna em ambiente não exposto a correntes de ar.

- Banho com $\mathrm{KMnO}_{4}$ a $1 / 40.000$ quando há lesões cutâneas generalizadas.

- Cuidadosa higiene oral com água bicarbonatada a 2 ou $3 \%$.

- Aplicação de compressas de álcool ou éter sobre as lesões herpéticas, seguida de embrocação com Violeta de Genciana.

- Higiene ocular com água boricada a $2 \%$, e se necessário, colocação de compressa oclusiva para profilaxia de úlcera de córnea.

- Limpeza das cavidades( nariz, orelha), segundo as necessidades do paciente.

- Curativos adequados das lesões cutâneas. $\left(\mathrm{KMnO}_{4} \mathrm{1} / 40.000\right.$, Furacin ou outros medicamentos).

8 - Observação e atendimento de problemas especiais.

- estado de consciência;

- agitação e outros sinais e sintomas específicos;

- alterações de comportamento;

- alergia a medicamentos;

- complicações da doença (artrites, broncopneumonia, gangrenas, etc);

- acuidade e condições dos órgãos dos sentidos;

— evolução do paciente; 
- evolução das sufusões hemorrágicas;

- queixas de dor, desconforto e mal estar e

- sinais e sintomas de agravamento do estado do paciente.

9 - Controles.

- Verificação da temperatura, pulso, respiração e pressão arterial, tantas vezes quantas necessárias.

- Controle das eliminações (líquido gástrico, urina, fezes, secreção nasal, vômitos).

10 - Auxílio no ajustamento do paciente à nova situação.

- Promoção da integração do paciente ao grupo social hospitalar.

- Explicação sobre a doença (natureza, mecanismo de transmissão, tratamento, profilaxia), isolamento e sistema hospitalar de isolamento.

11 - Orientação da família.

- Orientação abrangendo os itens constantes da orientação do paciente, acrescida da explicação sobre os cuidados a serem tomados no domicílio, consideradas as necessidades sentidas pelos familiares.

12 - Atenção e apoio psicológico.

- Utilização das técnicas de interação com o paciente (demonstrar real interesse pelo paciente; não demonstrar medo da doença meningocócica; ouvir o paciente; conversar e esclarecer dúvidas; diminuir os temores e a insegurança em relação à doença e a hospitalização; promover a integração do paciente ao grupo social hospitalar; etc.).

13 - Recreação.

- Promoção da recreação adequada às condições e preferências do paciente, com utilização dos recursos disponíveis.

14 - Cuidados especiais em relação a:

— vômitos, febre, oscilação da pressão arterial, distúrbios da respiração;

- sondas e drenos;

- prevenção de necroses, da coagulação intra-vascular disseminada, choque, convulsão, flebites;

- punção lombar;

- manutenção do equilíbrio ácido-básico e eletrolítico e

- exames laboratoriais. 
15 - Preparo para alta.

Deve ser iniciado precocemente procurando atender aos problemas e preocupações do paciente, suas reais condições e necessidades.

A orientação segura do paciente e da familia sobre os itens fundamentais da doença e da profilaxia são de importância capital.

16 - Manutenção de vigilância epidemiológica na comunidade.

O esquema de tratamento antibiótico é variável; no entanto, a média geral é de aproximadamente 10 dias.

No início do tratamento, a dependência do paciente é grande, exigindo maior contribuição da enfermagem na prestação de cuidados diretos de assistência e ajuda.

Com a evolução, esse tipo de cuidado vai diminuindo gradativamente em intensidade e extensão, sendo substituído pelos cuidados relativos a: observação, controle, orientação, supervisão, assistência psicológica e encaminhamentos.

Em casos de epidemia existem algumas diretrizes básicas a serem seguidas na orientação da comunidade quanto à profilaxia da doença meningocócica, que são abaixo apresentadas.

\section{PROFILAXIA DA DOENÇA MENINGOCÓCICA}

A - Recomendações gerais.

1 - Procurar obter conhecimentos corretos sobre a doença e selecionar informações.

2 - Orientar as pessoas menos esclarecidas, sem alarmar.

3 - Tomar os devidos cuidados e, na existência de casos suspeitos, orientar sobre a procura de assistência profissional adequada.

4 - Evitar aglomerações, principalmente em recintos fechados.

5 - Evitar acesso a doentes e hospitais.

6 - Manter as atividades normais.

B - Cuidados relativos ao ambiente e material (objetos, utensílios, etc.).

1 - Aeração (ventilação) adequada.

2 - Exposição ao sol.

3 - Limpeza rigorosa.

4 - Desinfeç̧ão do ambiente inclusive pias, banheiros, ralos, piso, etc., com desinfetantes comuns.

5 - Fervura ou esterilização de mamadeiras. 
C - Alimentação e hidratação.

1 - Alimentação nutritiva e preparada cuidadosamente.

2 - Suplementos vitamínicos naturais (frutas)

3 - Hidratação adequada.

D - Sono e repouso.

1 - Evitar excesso de atividades.

2 - Repousar adequadamente durante o dia.

3 - Sono adequado.

E - Higiene pessoal e vestuário.

1 - Cuidadosa higiene pessoal.

2 - Higiene oral freqüente (sem exagero).

3 - Higiene das cavidades:

- gargarejo com água, água e sabão, água e sal ou limão, água com sal e limão.

- limpeza das narinas: com água (Instilação de soro fisiológico para manutenção das funções protetoras da mucosa).

- olhos - higiene cuid'adosa e se desejado, utilização de colírio não medicamentoso.

4. - Lavagem das mãos

A freqüência dos cuidados higiênicos deverá ser de acordo com as necessidades do indivíduo (atividades, profissão, estado de saúde, ambiente, etc.).

5 - Vestuário adequado - Cuidados com as roupas.

F - Evitar exposição a temperaturas extremas (inclusive alimentos e bebidas geladas ou muito quentes).

G - Cuidados com os dentes e lesões da pele. Tratamento de amigdalites, sinusites, otites, etc.

H - Recreação em ambientes abertos ou ventilados.

I - Não utilização de auto-medicação, sobretudo de antibióticos.

J - Vacinação, quando houver.

\section{IV - CONSIDERAÇס̃ES FINAIS}

Diante do exposto, constata-se que no controle da doença meningocócica são importantes não só a assistência ao doente e comunicantes, como, também, as 
atividades de educação para saúde desenvolvidas pela equipe assistencial junto à comunidade, visando sobretudo a prevenção da doença, sua detecção precoce e tomada de conduta correta em relação ao tratamento.

KAMIYAMA, Y. Fundamentals of the nursing care for the patients with meningococic disease. Rev. Esc. Enf. USP, São Paulo, 15(2):161-171, 1981.

Analysis of the patients problems with meningococic disease and the basic mursing procedure in the control of that disease.

\section{REFERENCIAS BIBLIOGRAFICAS}

1. AMATO NETO, V. Meningites e sua problemática: palestra proferida no Curso de Atualização em Doenças Transmissiveis. São Paulo, ABEn., 1975. (mimeografado).

2. BASTOS, C. O. Meningite meningocócica. In: VERONESI, $R$. Doenças infecciosas e parasitárias. 6. ed. Rio de Janeiro, Guanabara Koogan, 1976. p. 530-5.

3. BITENCOURT, J. M. T. Meningites. In: VERONESI, R. Doenças infecciosas e parasitárias. 6. ed. Rio de aJneiro, Guarnabara Koogan, 1976. p. 504-29.

4. CUNHA, M. L. M. Problemas básicos de pacientes contagiosas: causas e consequências das doenças contagiosas: palestra proferida no Curso de graduação em enfermagem da EEUSP. São Paulo, 1976. (mimeografado).

5. Galvá, P. A. A. Tratamento das meningites meningocócica. Atual. Méd., São Paulo, Ediçăo Especial 11 (5): 55-62, ago. 1975

6. HORTA, W. A. Necessidades humanas básicas: considerações gerais. Enf. Novas Dimens., Săo Paulo, 1 (5): 266-8, 1975.

7. KAMTYAMA, Y. Assisténcia centrada na identidade social: aspectos psico-sociais do cuidado de enfermagem a pacientes de hepatite infecciosa. São Paulo, 1979. (Tese de Livre-Docéncla - Es. cola de Enfermagem da USP).

8. — — NAKAZAWA, C. K. Percepçảo do paciente contagioso sobre a sua doença e o isolamento: um estudo preliminar. Enf. Novas Dimens., São Paulo, 3 (1): $56-63,1977$.

9. ORGANIZACAO PANAMERICANA DE SAUDE. Profllaxia das doenças transmissivels. 11 . ed. Was. hington, 1973. (Publicaçăo Cientifica n.॰ 268).

10. SAO PAULO. Secretarła de Estado da Saúde. Manual de vigilância epidemiológica: normas e instruç̄es. Sāo Paulo, Centro de Informaç̋̄es de Saúde, 1978.

11. TIRIBA, A. C. Manifestaçōes clínicas e complicaçóes da meningite menincócica. Atual. med., Såo Paulo, Edição Especial, 11 (5): 34-41, ago. 1975. 